University of Windsor

Scholarship at UWindsor

2016

\title{
A strategic analysis of incorporating CSR into managerial incentive design
}

\author{
Kevin Li \\ University of Windsor \\ Junsong Bian \\ University of Windsor \\ Xiaolei Guo \\ University of Windsor
}

Follow this and additional works at: https://scholar.uwindsor.ca/odettepub

Part of the Business Commons

\section{Recommended Citation}

Li, Kevin; Bian, Junsong; and Guo, Xiaolei. (2016). A strategic analysis of incorporating CSR into managerial incentive design. Transportation Research, Part E: Logistics and Transportation Review, 86, 83-93.

https://scholar.uwindsor.ca/odettepub/141

This Article is brought to you for free and open access by the Odette School of Business at Scholarship at UWindsor. It has been accepted for inclusion in Odette School of Business Publications by an authorized administrator of Scholarship at UWindsor. For more information, please contact scholarship@uwindsor.ca. 
Transportation Research, Part E: Logistics and Transportation Review, 86 : $83-93,2016$.

\title{
A strategic analysis of CSR-related managerial incentive design
}

\author{
Junsong Bian \\ Odette School of Business, University of Windsor \\ 401 Sunset Ave., Windsor, Ontario, N9B 3P4, Canada \\ Email:bianj@uwindsor.ca \\ Kevin W. Li* \\ College of Economics and Management, Fuzhou University \\ Fuzhou, Fujian 350116, China \\ and \\ Odette School of Business, University of Windsor \\ 401 Sunset Ave., Windsor, Ontario, N9B 3P4, Canada \\ Email: kwli@uwindsor.ca \\ Xiaolei Guo \\ Odette School of Business, Cross-Border Institute, University of Windsor \\ 401 Sunset Ave., Windsor, Ontario, N9B 3P4, Canada \\ Email: guoxl@uwindsor.ca
}

\section{Acknowledgments:}

The authors would like to acknowledge the financial support from FedDev grants and their Natural Sciences and Engineering Research Council of Canada (NSERC) Discovery Grants. Kevin W. Li is also grateful for the financial support from the National Natural Science Foundation of China (Grant Nos: 71572040, 71272129, and 71271188) and the Japan Society for the Promotion of Science (JSPS) under its Invitation Fellowship program.

\footnotetext{
* Corresponding author. Telephone: 1 (519) 253-3000 ext 3456.
} 


\title{
A strategic analysis of incorporating CSR into managerial incentive design
}

\begin{abstract}
A strategic analysis is conducted to incorporate corporate social responsibility (CSR) considerations into managerial incentive design in a duopoly where each firm comprises an owner and a manager. Consumer surplus is adopted to represent the firms' CSR concerns and a CSR-related incentive is introduced to accommodate both profit and consumer surplus. Bertrand and Cournot competition modes are discussed with the firms' products being complementary, independent, or substitutable. We first examine the equilibrium of CSR-related incentive design and, then, analyze how CSR-related incentives affect the firms' profitability and CSR performance, measured by consumer surplus and social welfare.

Keywords: Corporate social responsibility; Managerial incentive design; Bertrand competition; Cournot competition; Product relationship; Equilibrium.
\end{abstract}

\section{Introduction}

Increasing attention has been paid to corporate social responsibility (CSR) in both practice and academia. A large number of companies issue various CSR statements/activities in their annual reports. A CSR trend report by PriceWaterhouseCoopers suggested that the number of companies with CSR statements on their websites increased to $81 \%$ at the end of July 2010 from $75 \%$ at the end of July 2009. Another international survey by KPMG in 2008 showed that nearly $80 \%$ of the world's largest 250 companies disclosed CSR reports, up from $50 \%$ in 2005 . In job markets, $88 \%$ of the job seekers would choose employers based on strong CSR values and $86 \%$ would consider leaving if the companies' CSR values no longer met their expectations (PriceWaterhouseCoopers, 2011). The empirical studies above indicate that CSR has become an important consideration from the perspective of various entities such as shareholders, managers and consumers. Similarly, Vogel (2005) pointed out that $70 \%$ of the global chief executives believe that CSR activities are vital to their companies' profitability, suggesting that CSR is critical to firms' overall strategy and success. Furthermore, Lee (2008) observed that, although the link between CSR and firms' profitability is getting tighter, but it remains unclear whether it is positive or negative. Motivated by these works, we attempt to provide a possible explanation 
for the relationship between CSR and firms' profitability from a theoretical perspective.

Following the research in Goering (2007) and Kopel and Brand (2012), this paper adopts consumer surplus as a proxy of the firms' CSR concerns and introduces a CSR-related incentive combining both profitability and consumer surplus. We study the strategic design of such CSRrelated incentives in a duopoly where each firm consists of an owner and a manager. We can find duopolistic competition in the Canadian logistics industry such as the Canadian National and Canadian Pacific Railways. It is supposed that each firm owner can choose a weight on CSR to influence its manager's market decision. First, we discuss whether the profit-driven firm owners have motivation to offer their managers the CSR-related incentives. Second, we examine the effect of the CSR-related incentives on the firms' profitability and CSR performance as reflected by consumer surplus and social welfare. We consider two market competition modes, Bertrand and Cournot, and three product relationships: complementary, independent and substitutable products. Bertrand and Cournot competition modes are both common in the logistics industry (Brander and Zhang, 1990, 1993; Oum et al., 1993; Lijesen, 2004). Specifically, our research questions are: Can the CSR-related incentives endogenously arise in equilibrium? If so, what is the impact of such incentives on firms' profitability, consumer surplus and social welfare? How do the competition mode and product relationship affect the equilibrium results and why?

Due to separation of ownership and management, contemporary firms are often characterized by managerial delegation, where shareholders can induce professional managers to operate their firms based on certain managerial incentives. Furthermore, the importance of integrating CSR into managerial incentives has been discussed in existing research. Business experts such as management scholars and compensation advisors tend to suggest a change in the CEO compensation contract to incorporate CSR as part of the CEO remuneration (Coombs and Gilley, 2005; Mahoney and Thorn, 2006). As reported by Dahlsrud (2008), despite many debates on what CSR really embraces, stakeholders' concerns are one of the most important dimensions of CSR and consumers are admittedly among the most influential stakeholders of a firm. Russell Reynolds Associates reported that 76 percent of investors consider incentive mechanisms as either important or very important when dealing with social issues (Berrone and Gomez-Mejia, 2009).

Although previous research discussed CSR from the perspective of enhancing firms' public image, we take a different stance by examining CSR-related managerial incentive design from a 
strategic competition perspective, which is an important topic (Porter and Kramer, 2006). A key finding is that the competing profit-driven owners always design the CSR-related incentive in equilibrium (which is reduced to the pure-profit incentive with independent products). Furthermore, for correlated products, we show that the owners' strategic design of CSR-related incentives does not necessarily enhance their profitability, but they always employ such incentives in equilibrium for strategic competition purposes. Specifically, we find that the CSRrelated incentives serve as the owners' strategic competition device to obtain more advantage (under Cournot competition with complementary products and Bertrand competition with substitutable products) or evade disadvantage (under Cournot competition with substitutable products and Bertrand competition with complementary products). Compared with the benchmark pure-profit incentives, the CSR-related incentives can either increase or decrease the firms' profitability, consumer surplus and social welfare. In the case that both firms' profits are worsened by engaging in CSR-related incentives, the firms are forced to do so because they are trapped in a Prisoner's Dilemma where the scenario that both firms' profits are better off without considering CSR is not an equilibrium. In addition, if one firm embraces CSR-related incentives but the other does not, the latter's profit will be even further worsened. The managerial insights behind our results are as follows: First, whether the firms enhance their profitability by designing the CSR-related incentives depends on both product relationship and the competition mode. Second, whether the CSR-related managerial incentive design is beneficial to consumer surplus and social welfare depends only on the competition mode.

The remainder of the paper is organized as follows. Section 2 briefly reviews the previous literature related to this study. Sections 3 and 4 discuss the endogenous design of the CSRrelated incentives under Cournot and Bertrand competition modes, respectively. The paper concludes in Section 5 with some remarks and suggestions for future research.

\section{Literature Review}

In general, this paper is related to two strands of literature: CSR and managerial incentive design. First, CSR has attracted significant attention since 1960s, mainly driven by forwardthinking academics and social movements such as consumer rights and environmental regulations, especially in the US. Initially, in the 1960s and 1970s, CSR was motivated by social rather than economic considerations. Firms were trying to be philanthropic instead of expecting 
more profit from their CSR activities. Later, CSR research emphasized the relationship between CSR and firm profitability (Vogel, 2005). Analogously, Lee (2008) observed that the link between CSR and firms' profits is getting tighter, but it remains unclear whether it is positive or negative. For more understanding on CSR, readers are referred to Carroll and Shabana (2010) and Schreck (2011) for excellent reviews. The aforementioned studies are either qualitative or empirical, while we examine CSR-related incentive design using an analytical model, which is identified as an important topic by Lee (2008). By considering CSR-related managerial incentive design from the perspective of strategic competition rather than philanthropy, we provide a possible theoretical explanation for the link between CSR and firms' profitability.

Regarding other theoretical works, Goering (2008a) examined the durability decision of a durable-goods monopoly with and without consumer welfare related social concern and found that such social concern increases product durability if the firm can commit to its stakeholders, while the opposite emerges otherwise. Goering (2010) further explored whether social concern can increase a durable-goods firm's profit and showed that the result depends on whether the firm has the ability to make commitments in the sales market. Two differences exist between our research and the aforesaid studies. First, existing research considered a monopolistic market, while we consider a duopoly under two competition modes. Second, we integrate CSR into managerial delegation in a private duopoly and discuss how such CSR-related incentive design affects the firms' profitability, consumer surplus and social welfare, while Goering (2008a; 2010) did not consider managerial incentive design. Barcos et al. (2013) examined the relationship between inventory investment and firms' CSR activities directed toward stakeholders. Apart from the difference in research techniques, our focus is on the strategic design of the CSR-related managerial incentives, whereas they discussed operational consequences of certain CSR activities. Ye and Mukhopadhyay (2013) investigated altruistic behavior with CSR-related social concerns between two competing vertically-differentiated firms. Our paper differs as we focus on CSR-related incentive design, which is not considered by Ye and Mukhopadhyay (2013). Unlike existing research, we focus on the endogenous design of CSR-related managerial incentives with horizontal product differentiation under different competition modes.

CSR has also been studied in supply chains, either qualitatively and empirically (Boyd et al., 2005, 2007; Amaeshi et al., 2008; Carter et al., 2000; Carter and Jennings, 2002; Miao et al., 2012; Ageron et al., 2012), or using analytical models (Brand and Grothe, 2013; Cruz, 2008; 
Cruz and Wakolbinger, 2008; Goering, 2012, 2013; Hsueh, 2015; Ni et al., 2010; Ni and Li, 2012; Panda, 2014; Panda et al., 2015; Xia et al., 2015). While the aforementioned works studied CSR in supply chains, we discuss whether duopolistic firms have social concerns under different modes of horizontal competition. Furthermore, we combine the prevalent managerial incentives with CSR and explore whether the firms are engaged in the CSR-related incentives in equilibrium and how such incentives affect the firms' profitability, consumer surplus and social welfare.

The second strand of related research lies in managerial incentive design literature. The pioneer works in this respect are reported by Vickers (1985), Fershtman (1985), Fershtman and Judd (1987) and Sklivas (1987). This body of literature explored the strategic effect of incentives with endogenous weights on sales and firm profitability. Subsequently, extensive research has emerged by designing managerial incentives based on relative performance (Joh, 1999; Aggarwal and Samwick, 1999; Miller and Pazgal, 2001, 2002; Asseburg and Hofmann, 2010), market share (Jansen et al., 2007, 2012; Ritz, 2008; Wang et al., 2009), process innovation and product quality (Ishibashi, 2001; Overvest and Veldman, 2008; Veldman and Gaalman, 2014; Veldman et al., 2014), to name a few. Our research differs from the above works in that we consider the CSR-related managerial incentives incorporating consumer surplus into profitability, which enable us to examine whether firms have social concerns on consumers and how the outcomes vary with competition modes and product relationships. Some studies focused on sales incentive design in the context of mixed oligopolies where not-for-profit public firms compete with private firms (Barros, 1995; White, 2001; Heywood and Ye, 2009; Tomaru et al., 2011; Du et al., 2013; Kopel and Marini, 2014). In contrast, we focus on two competing private firms' CSR-related incentive design. For more research on strategic incentive design, readers are referred to Sengul et al. (2012).

Yet, limited research investigated CSR-related managerial incentives. For instance, Goering (2007) examined a mixed duopoly consisting of a public not-for-profit firm and a profit-driven private firm, where the not-for-profit firm designs its managerial incentives based on consumer surplus. Within the same mixed duopoly, Kopel and Brand (2012) extended the work of Goering (2007) by allowing the private firm to design its sales-oriented managerial incentive. Goering (2008b) discussed the welfare effect in a mixed oligopoly and found that a shift from the pureprofit behavior by a not-for-profit firm may decrease social welfare. Since CSR is not merely 
restricted to public or not-for-profit firms, our research differs from the works above in several aspects. First, we examine two private firms' endogenous design of the CSR-related incentives, while their research assumed that only the public firm adopts CSR-related incentives and the private firm is merely sales driven. Second, we consider both Cournot and Bertrand competition modes with differentiated goods, but they only studied Cournot competition with homogenous goods.

\section{The model and incentive analysis under Cournot competition}

Consider two firms, firms 1 and 2, characterized by separate management and ownership. Each firm (firm $i$ ) consists of an owner (owner $i$ ) who owns the firm and a manager (manager $i$ ) who makes market decisions based on the incentive contract designed by the corresponding firm owner.

Following Singh and Vives (1984), we assume the standard consumer surplus as

$$
C S=\overbrace{\left[\alpha\left(q_{i}+q_{j}\right)-\frac{1}{2}\left(q_{i}^{2}+q_{j}^{2}\right)-\beta q_{i} q_{j}\right]}^{\text {gross utility }}-\overbrace{\left(p_{i} q_{i}+p_{j} q_{j}\right)}^{\text {expenditure }}, i, j=1,2 ; i \neq j,
$$

where $C S$ stands for consumer surplus, and $p_{i}$ and $q_{i}(i=1,2)$ denote product $i$ 's retail price and quantity, respectively. Note that the first term of the right-hand side of Eq. (1) denotes the gross utility of consumers before purchase, while the second term represents consumers' total payment for purchasing $q_{i}(i=1,2)$ units of products. Overall, the difference between these two terms denotes the consumer surplus after purchase. This form of utility function yields the linear demand structure as shown in Eq. (2) (Singh and Vives, 1984).

Maximizing Eq. (1) with respect to quantities, we obtain the inverse demand as

$$
p_{i}\left(q_{i}, q_{j}\right)=\alpha-q_{i}-\beta q_{j}, i, j=1,2 ; i \neq j
$$

$\alpha$ is the reservation price and $\beta \in(-1,1)$ measures product differentiation with $\beta \in(-1,0), 0$ and $\beta \in(0,1)$ representing complementary, independent, and substitutable products, respectively.

Inverting Eq. (2), we obtain the direct demand as

$$
q_{i}\left(p_{i}, p_{j}\right)=\frac{(1-\beta) \alpha-p_{i}+\beta p_{j}}{1-\beta^{2}}, i, j=1,2 ; i \neq j .
$$


This section adopts Eq. (2) to examine CSR-related incentive design under Cournot competition. The case of Bertrand competition is analyzed in Section 4 by using Eq. (3). To focus on the strategic effect, both firms' marginal costs are normalized to zero, which also helps to avoid unnecessary complexity without qualitatively changing our results.

Based on the seminal works of Fershtman (1985), Fershtman and Judd (1987) and Sklivas (1987), we consider whether the profit-driven firm owners endogenously design the CSR-related incentives in equilibrium. Each manager's compensation structure contains a fixed lump-sum payment $F_{i}$ plus a variable component that is proportional to a linear combination of profit and consumer surplus $\Pi_{i}+\theta_{i} C S$ under the CSR-related incentive, where $\Pi_{i}$ and $\theta_{i}$ are firm $i$ 's profit and incentive parameter/weight, respectively. Thus, each manager's salary is given by $F_{i}+\lambda_{i} \Pi_{i}$ under the pure-profit incentive or $F_{i}+\lambda_{i}\left(\Pi_{i}+\theta_{i} C S\right)$ under the CSR-related incentive, where $\lambda_{i}$ is a positive scale parameter to the variable portion of the compensation. Without loss of generality, it is assumed that each manager's highest reservation utility from outside opportunities is $\underline{U}$. Mathematically, owner $i$ 's problem under the CSR-related incentive is given by

$$
\left\{\begin{array}{l}
\underset{F_{i}, \lambda_{i}, \theta_{i}}{\operatorname{Max}} \Pi_{O i}=\Pi_{i}-\left[F_{i}+\lambda_{i}\left(\Pi_{i}+\theta_{i} C S\right)\right] \\
\text { s.t. } \\
U_{M i}=F_{i}+\lambda_{i}\left(\Pi_{i}+\theta_{i} C S\right) \geq \underline{U}
\end{array},\right.
$$

where the subscripts ' $O i$ ' and ' $M i$ ' denote owner $i$ and manager $i$, respectively. Apparently, each owner will set the values of $F_{i}$ and $\lambda_{i}$ to adjust its manager's compensation such that the constraint in Eq. (4) becomes binding, i.e., $F_{i}=\underline{U}-\lambda_{i}\left(\Pi_{i}+\theta_{i} C S\right)$. This incentive structure is a standard two-part tariff contract which will not distort the managers' decisions. Based on this, manager $i$ 's problem under the CSR-related incentive is to maximize his/her compensation $U_{M i}=\Pi_{i}+\theta_{i} C S$ by setting a price (or quantity) and owner $i$ 's problem is to maximize $\Pi_{O i}=\Pi_{i}-\underline{U}$ by setting an optimal CSR weight. Since $\underline{U}$ is a constant, owner $i$ 's problem is equivalent to profit maximization.

Based on the discussions above, we see that each manager's problem is to maximize its compensation stipulated by the CSR incentive and each owner's objective is to choose the 
optimal incentive weight for profit maximization.

We consider the following sequence of decisions. In the first stage, the owners simultaneously decide the endogenous weights of the CSR-related incentives for profit maximization. In the second stage, given the CSR-related incentives offered by their owners, the managers compete by simultaneously setting the quantities (or prices under Bertrand competition in Section 4) of the products in the product market. In what follows, we employ backward induction to ensure sub-game perfection.

Under the CSR-related incentives, the managers' problems are given by

$$
\operatorname{Max}_{q_{i}} U_{M i}^{Q}=p_{i}\left(q_{i}, q_{j}\right) q_{i}+\theta_{i} C S, i, j=1,2 ; i \neq j .
$$

where the superscript ' $Q$ ' indicates Cournot competition mode.

The first-order conditions (FOCs) can be obtained by substituting the inverse demand into Eq. (5) and differentiating each manager's objective with respect to its corresponding quantity. Solving the FOCs yields the optimal responses as

$$
\left\{\begin{array}{l}
q_{1}^{Q}\left(q_{2}, \theta_{1}\right)=\frac{\alpha-\beta\left(1-\theta_{1}\right) q_{2}}{2-\theta_{1}} \\
q_{2}^{Q}\left(q_{1}, \theta_{2}\right)=\frac{\alpha-\beta\left(1-\theta_{2}\right) q_{1}}{2-\theta_{2}}
\end{array} .\right.
$$

The intersection of the managers' reactions in Eq. (6) determines the equilibrium quantities as functions of incentive weights $\theta_{i}(i=1,2)$ :

$$
\left\{\begin{array}{l}
q_{1}^{Q}\left(\theta_{1}, \theta_{2}\right)=\frac{\left[\left(2-\theta_{2}\right)-\beta\left(1-\theta_{1}\right)\right] \alpha}{\left(2-\theta_{1}\right)\left(2-\theta_{2}\right)-\beta^{2}\left(1-\theta_{1}\right)\left(1-\theta_{2}\right)} \\
q_{2}^{Q}\left(\theta_{1}, \theta_{2}\right)=\frac{\left[\left(2-\theta_{1}\right)-\beta\left(1-\theta_{2}\right)\right] \alpha}{\left(2-\theta_{1}\right)\left(2-\theta_{2}\right)-\beta^{2}\left(1-\theta_{1}\right)\left(1-\theta_{2}\right)}
\end{array} .\right.
$$

We first denote the benchmark pure-profit (no CSR) incentives with $\bar{\theta}_{i}^{Q}=0(i=1,2)$. The optimal solutions under this case can be obtained by substituting $\bar{\theta}_{i}^{Q}=0(i=1,2)$ into Eq. (7) and then backward. We summarize the results under the benchmark pure-profit (no CSR) incentives in the second column of Table 1. 
In order to compare with the benchmark pure-profit (no CSR) incentives, in what follows we solve for optimal CSR incentive weights. Substituting Eq. (7) into the owners' profit functions and solving them, we have

$$
\theta_{i}^{Q}=\frac{2+2 \beta+\beta^{2}-\sqrt{4+8 \beta+4 \beta^{2}+\beta^{4}}}{2(1+\beta)}, i=1,2 .
$$

Based on Eq. (8), other optimal solutions under the CSR-related incentives are obtained and summarized in the last column of Table 1.

Table 1. Solutions under Cournot competition.

\begin{tabular}{|c|c|c|}
\hline & Pure-profit incentives & CSR-related incentives \\
\hline $\begin{array}{l}\text { Incentive } \\
\text { weight }\end{array}$ & 0 & $\frac{2+2 \beta+\beta^{2}-\sqrt{4+8 \beta+4 \beta^{2}+\beta^{4}}}{2(1+\beta)}$ \\
\hline Price & $\frac{\alpha}{2+\beta}$ & $\frac{\left(\sqrt{4+8 \beta+4 \beta^{2}+\beta^{4}}-2 \beta-\beta^{2}\right) \alpha}{\sqrt{4+8 \beta+4 \beta^{2}+\beta^{4}}+2-\beta^{2}}$ \\
\hline Quantity & $\frac{\alpha}{2+\beta}$ & $\frac{2 \alpha}{2-\beta^{2}+\sqrt{4+8 \beta+4 \beta^{2}+\beta^{4}}}$ \\
\hline Profit & $\frac{\alpha^{2}}{(2+\beta)^{2}}$ & $\frac{2\left(\sqrt{4+8 \beta+4 \beta^{2}+\beta^{4}}-2 \beta-\beta^{2}\right) \alpha^{2}}{\left(\sqrt{4+8 \beta+4 \beta^{2}+\beta^{4}}+2-\beta^{2}\right)^{2}}$ \\
\hline $\begin{array}{l}\text { Consumer } \\
\text { surplus }\end{array}$ & $\frac{(1+\beta) \alpha^{2}}{(2+\beta)^{2}}$ & $\frac{4(1+\beta) \alpha^{2}}{\left(\sqrt{4+8 \beta+4 \beta^{2}+\beta^{4}}+2-\beta^{2}\right)^{2}}$ \\
\hline $\begin{array}{l}\text { Social } \\
\text { welfare }\end{array}$ & $\frac{(3+\beta) \alpha^{2}}{(2+\beta)^{2}}$ & $\frac{4\left(\sqrt{4+8 \beta+4 \beta^{2}+\beta^{4}}+1-\beta-\beta^{2}\right) \alpha^{2}}{\left(\sqrt{4+8 \beta+4 \beta^{2}+\beta^{4}}+2-\beta^{2}\right)^{2}}$ \\
\hline
\end{tabular}

We now present the equilibrium incentives under Cournot competition.

Proposition 1. Under Cournot competition, $\theta_{i}^{Q} \geq 0$, where the equality holds if and only if $\beta=0$. Compared to the pure-profit incentives, the CSR-related incentives enhance both firms' profitability if $\beta \in(-1,0)$ but make them worse off if $\beta \in(0,1)$. 
Proof. See Appendix.

Proposition 1 indicates that, under the Cournot competition mode, both owners choose the pure-profit incentives $\left(\bar{\theta}_{i}^{Q}=0\right)$ in equilibrium if the products are independent $(\beta=0)$. In this case, there is no competition between the two firms in the product market (i.e., in Eq. (6), $q_{i}$ does not interact with $q_{j}$ ), and each firm is a monopoly and each owner's interference using a non-zero incentive weight will make its objective deviate from the optimal profitability. Thus, the owners engage in the pure-profit incentives by setting $\bar{\theta}_{i}^{Q}=0$ in equilibrium without interfering with their respective managers' decisions.

When the products are complementary or substitutable $(\beta \in(-1,0) \cup(0,1))$, each owner chooses the CSR-related incentive in equilibrium, with a positive weight on CSR. It is standard in managerial economics that the Cournot competition is often not as aggressive as desired (Miller and Pazgal, 2001). In this case, each owner's CSR-related incentive design serves as its more aggressive competition. For this purpose, each owner has to set a positive weight on CSR (with its manager being rewarded) to induce a higher quantity since a negative weight penalizing CSR leads to a lower quantity, which means even less competition. Specifically, given that owner 1 chooses the pure-profit incentive, owner 2 will act more aggressively by choosing the CSR-related incentive to make more profit, which will benefit (hurt) owner 1 if the products are complementary (substitutable). The logic is as follows: as shown in Eq. (6), an increase in one firm's quantity will increase (reduce) the quantity of the other firm if the products are complementary (substitutable). In anticipation of this, owner 1 will further intensify the competition by switching from the pure-profit incentive to the CSR-related incentive to pursue more profit (with complements), or avoid profit loss (with substitutes).

Generally speaking, the equilibrium CSR-related incentives do not necessarily lead to higher profit for the owners compared to the benchmark pure-profit incentives. First, the firms benefit from engaging in the CSR-related incentives when products are complementary. This is due to the fact that, if the products are complementary $(\beta \in(-1,0))$, the firms' quantity decisions are mutually enhancing: the increase of one firm's quantity will simultaneously enhance the quantity of the other firm (Eq. (6)). On the other hand, when products are substitutable, the CSR-related incentives make both owners' profitability worse off. The reason is as follows: if the products are 
substitutable $(\beta \in(0,1)$ ), the firms' quantity decisions are in conflict with each other, i.e., the increase of one firm's quantity will reduce the quantity supply of the other firm (Eq. (6)).

Proposition 2. $\theta_{i}^{Q}(i=1,2)$ increases as products become more substitutable or complementary, i.e., $\theta_{i}^{Q}$ increases in $|\beta|$.

Proof. See Appendix.

Proposition 2 states that, under Cournot competition, the equilibrium weights of the CSRrelated incentives increase as products' relationship (substitutable or complementary) level increases. This is explained as follows. In Cournot competition, the owners employ the CSRrelated incentives to overcome the under-aggressiveness of the managers' quantity decisions. As the products become more related (substitutable or complementary), the interdependence between the managers' interaction become stronger, which motivates the owners to set a higher incentive weight to induce the managers to make more aggressive decisions.

Let $C S^{Q}$ and $\overline{C S}^{Q}$, respectively, stand for the equilibrium consumer surplus with CSRrelated and pure-profit incentives under Cournot competition.

Proposition 3. Under Cournot competition, the CSR-related incentives tend to increase consumer surplus compared with the pure-profit incentives, i.e., $C S^{Q} \geq \overline{C S}^{Q}$ with equality holding if and only if $\beta=0$.

Proof. See Appendix.

When $\beta=0$, Proposition 1 indicates the CSR-related incentives are reduced to pure-profit incentives and, hence, consumer surplus is identical for the two cases. Next, our interpretation focuses on the case with correlated products $(\beta \neq 0)$. Proposition 3 suggests that, under Cournot competition with correlated products, the CSR-related incentives yield higher consumer surplus than the pure-profit incentives do. As the CSR incentive weights are positive in this case, both firms can be interpreted as consumer-friendly. Under the CSR-related incentives, each firm always produces a higher quantity level than that under the pure-profit incentives, thereby resulting in higher consumer surplus for correlated (substitutable or complementary) products.

Let $S W^{Q}$ and $\overline{S W}^{Q}$, respectively, represent the equilibrium social welfare with CSRrelated and pure-profit incentives under Cournot competition. 
Proposition 4. Under Cournot competition, the CSR-related incentives tend to increase social welfare compared with the pure-profit incentives, i.e., $S W^{Q} \geq \overline{S W}^{Q}$ with equality holding if and only if $\beta=0$.

Proof. See Appendix.

Once again, the special case of $\beta=0$ results in the same social welfare for the two incentives. For correlated products, Proposition 4 demonstrates that the CSR-related incentives yield higher social welfare than the pure-profit incentives do under Cournot competition. The reason is as follows. Social welfare comprises firms' profits and consumer surplus. When the products are substitutable, our results suggest that, while both firms' profits decrease, the increase in consumer surplus (Proposition 3) is more than enough to offset the decrease in profit (Proposition 1). On the other hand, when the products are complementary, the firms' profits and consumer surplus are both higher under the CSR-related incentives, yielding higher social welfare than that under the pure-profit incentives. In sum, under Cournot competition, social welfare is always higher under the CSR-related incentives than under the pure-profit incentives as long as the products are substitutable or complementary.

\section{Incentive analysis under Bertrand competition}

In this section, we proceed to examine the CSR-related incentive design under Bertrand competition. The managers' problems are given by

$$
\underset{p_{i}}{\operatorname{Max}_{M i}} U_{M i}^{P}=p_{i} q_{i}\left(p_{i}, p_{j}\right)+\theta_{i} C S, i, j=1,2 ; i \neq j .
$$

where the superscript ' $P$ ' indicates the Bertrand competition mode.

Substituting the inverse demand functions into Eq. (9) and solving the resulting FOCs yield the optimal responses as

$$
\left\{\begin{array}{l}
p_{1}^{P}\left(p_{2}, \theta_{1}\right)=\frac{\alpha(1-\beta)\left(1-\theta_{1}\right)+\beta\left(1-\theta_{1}\right) p_{2}}{2-\theta_{1}} \\
p_{2}^{P}\left(p_{1}, \theta_{2}\right)=\frac{\alpha(1-\beta)\left(1-\theta_{2}\right)+\beta\left(1-\theta_{2}\right) p_{1}}{2-\theta_{2}}
\end{array} .\right.
$$

The intersection of the managers' reaction functions in Eq. (10) determines the equilibrium prices as functions of incentive weights $\theta_{i}(i=1,2)$ : 


$$
p_{i}^{P}\left(\theta_{i}, \theta_{j}\right)=\frac{(1-\beta)\left(1-\theta_{i}\right)\left[\left(2-\theta_{j}\right)-\beta\left(1-\theta_{j}\right)\right] \alpha}{\left(2-\theta_{i}\right)\left(2-\theta_{j}\right)-\beta^{2}\left(1-\theta_{i}\right)\left(1-\theta_{j}\right)}, i, j=1,2 ; i \neq j .
$$

Similar to Cournot competition, we denote the benchmark pure-profit (no CSR) incentives under Bertrand competition with $\bar{\theta}_{i}^{P}=0(i=1,2)$ for comparison. The optimal solutions under the pure-profit (no CSR) incentives can be obtained by substituting $\bar{\theta}_{i}^{P}=0(i=1,2)$ into the relevant expressions above. We summarize the benchmark results in the second column of Table 2.

Now we solve for the optimal CSR incentive weights. Substituting Eq. (11) into the owners' profit functions and solving them, we obtain

$$
\theta_{i}^{P}=\frac{\sqrt{1-\beta^{2}}-1}{\sqrt{1-\beta^{2}}}, i=1,2 .
$$

Based on Eq. (12), remaining solutions are derived and summarized in the last column of Table 2.

Table 2. Solutions under Bertrand competition.

\begin{tabular}{|c|c|c|}
\hline $\begin{array}{c}\text { Incentive } \\
\text { weight }\end{array}$ & Pure-profit incentives & CSR-related incentives \\
\hline Price & $\frac{\alpha}{(1+\beta)(2-\beta)}$ & $\frac{\sqrt{1-\beta^{2}}-1}{\sqrt{1-\beta^{2}}}$ \\
\hline Quantity & $\frac{(1-\beta) \alpha}{2-\beta}$ & $\frac{\left.(1-\beta)+\sqrt{1-\beta^{2}}\right] \alpha}{2\left(\sqrt{1-\beta^{2}}+1\right)}$ \\
\hline Profit & $\frac{(1-\beta) \alpha^{2}}{(1+\beta)(2-\beta)^{2}}$ & $\frac{\left(1+\beta+\sqrt{1-\beta^{2}}\right) \alpha}{2(1+\beta)\left(\sqrt{1-\beta^{2}}+1\right)}$ \\
\hline $\begin{array}{c}\text { Consumer } \\
\text { surplus }\end{array}$ & $\frac{\alpha^{2}}{(1+\beta)(2-\beta)^{2}}$ & $\frac{\left(1+\beta+\sqrt{1-\beta^{2}}\right)\left(1+\beta+\sqrt{1-\beta^{2}}\right) \alpha^{2}}{4(1+\beta)\left(\sqrt{1-\beta^{2}}+1\right)^{2}}$ \\
\hline
\end{tabular}




\begin{tabular}{|c|c|c|}
\hline $\begin{array}{c}\text { Social } \\
\text { welfare }\end{array}$ & $\frac{(3-2 \beta) \alpha^{2}}{(1+\beta)(2-\beta)^{2}}$ & $\frac{\left(1+\beta+\sqrt{1-\beta^{2}}\right)\left(3-\beta+3 \sqrt{1-\beta^{2}}\right) \alpha^{2}}{4(1+\beta)\left(\sqrt{1-\beta^{2}}+1\right)^{2}}$ \\
\hline
\end{tabular}

Similar to Cournot competition in Section 3, we have

Proposition 5. Under Bertrand competition, $\theta_{i}^{P} \leq 0$, where the equality holds if and only if $\beta=0$. Compared with the pure-profit incentives, the CSR-related incentives lower both firms' profitability if $\beta \in(-1,0)$ and helps them achieve a win-win outcome if $\beta \in(0,1)$.

Proof. See Appendix.

Proposition 5 reports that the equilibrium is reduced to the pure-profit incentives $\left(\theta_{i}^{P}=0\right)$ if the products are independent $(\beta=0)$ under Bertrand competition. The reason is the same as that under Cournot competition: when the products are independent, there is no competition in the product market and both firms are independent monopolies ( $p_{i}$ and $p_{j}$ do not interact with each other in Eq. (10) when $\beta=0$ ).

On the other hand, both owners choose the CSR-related incentive strategies in equilibrium if the products are complementary or substitutable $(\beta \in(-1,0) \cup(0,1))$. Due to the fact that the Bertrand mode leads to intense competition in the product market, both owners have incentives to lower the degree of competition (Miller and Pazgal, 2001). To this end, each owner sets a negative weight on CSR to penalize its manager with the purpose of inducing higher retail prices to mitigate competition (a positive weight on CSR leads to lower prices and even more intense competition). Specifically, if owner 1 chooses the pure-profit incentive, owner 2 will choose the CSR-related incentive to soften the competition for better profit, which will hurt (benefit) owner 1 if the products are complementary (substitutable). The reason is as follows: as shown in Eq. (10), the increase in a firm's price will decrease (increase) the price of the other firm if the products are complementary (substitutable). Knowing this, owner 1 will further soften the competition by shifting from the pure-profit incentive to the CSR-related incentive to avert disadvantage with complementary products or enhance its profitability with substitutable products. 
Similar to Proposition 1, compared with the benchmark pure-profit incentives, the equilibrium CSR-related incentives do not necessarily guarantee better profits for the owners. When the products are complementary $(\beta \in(-1,0))$, the CSR-related incentives make both firm owners' profitability worse off because the firms' price decisions are in mutual conflict, i.e., the increase of one firm's price will reduce the price of the other firm (Eq. (10)). In contrast, when products are substitutable $(\beta \in(0,1))$, both owners benefit from engaging in the CSR-related incentives as the firms' price decisions are mutually enhancing: the rise of one firm's price will simultaneously increase the price of the other firm (Eq. (10)).

Putting Propositions 1 and 5 together, one can see that the impact of the CSR-related incentives on the firms' profitability is opposite for complementary (substitutable) products under Bertrand and Cournot competition modes. In other words, compared with the benchmark pure-profit incentives, whether the CSR-related incentives enhance the firms' profitability depends on both product relationship and the competition mode. This result sheds clear insights for firm owners: a win-win scenario is achievable and a lose-lose situation can be avoided by carefully examining their competition strategy and product relationship and, then designing an appropriate managerial incentive accordingly.

Proposition 6. $\theta_{i}^{P}(i=1,2)$ decreases as the products become more substitutable or complementary, i.e., $\theta_{i}^{P}$ decreases in $|\beta|$.

Proof. See Appendix.

Proposition 6 suggests that, under Bertrand competition, the equilibrium weights on the CSR-related incentives decrease in the degree of product differentiation. The intuition is as follows. In Bertrand competition, both owners employ the CSR-related incentives to soften the excessive competition. As the products become more related (substitutable or complementary), the interdependence between the managers' decisions becomes stronger, which motivates the owners to set more negative incentive weights to induce the managers to make less competitive decisions.

Let $C S^{P}$ and $\overline{C S}^{P}$, respectively, denote the equilibrium consumer surplus with CSR-related and pure-profit incentives under Bertrand competition. 
Proposition 7. Under Bertrand competition, the CSR-related incentives tend to decrease consumer surplus compared with the pure-profit incentives, i.e., $C S^{P} \leq \overline{C S}^{P}$ with equality holding if and only if $\beta=0$.

Proof. See Appendix.

The result in Proposition 7 is in contrast to that of Proposition 3. The special case of $\beta=0$ is trivial. For correlated products $(\beta \neq 0)$, Proposition 7 suggests that, under Bertrand competition, consumer surplus is higher under the pure-profit incentives than that under the CSR-related incentives, which is reasonable as a negative CSR incentive weight implies that owners are unfriendly to consumers (and, hence, CSR). This implies that, under Bertrand competition, the CSR-related incentives are always detrimental to consumer surplus as long as the products are not independent. Combining with Proposition 3, for correlated products, we can see that whether the CSR-related incentives increase or decrease consumer surplus only depends on the competition mode.

Let $S W^{P}$ and $\overline{S W}^{P}$, respectively, express the equilibrium social welfare with CSR-related and pure-profit incentives under Bertrand competition.

Proposition 8. Under Bertrand competition, the CSR-related incentives tend to decrease social welfare compared with the pure-profit incentives, i.e., $S W^{P} \leq \overline{S W}^{P}$ with equality holding if and only if $\beta=0$.

Proof. See Appendix.

Once again, the special case of independent products $(\beta=0)$ leads to identical social welfare for the two incentives as CSR-related incentives are reduced to pure-profit profits. For correlated products, in contrast to Proposition 4, Proposition 8 shows that social welfare under CSR-related incentives is lower than that under pure-profit incentives. The reason is as follows: when the products are substitutable, the increase in the firms' profit (Proposition 5) is insufficient to offset the decrease in consumer surplus (Proposition 7). On the other hand, when the products are complementary, both the firms' profits and consumer surplus are reduced, leading to lower social welfare. Therefore, under Bertrand competition, social welfare is always lower under consumer-unfriendly CSR-related incentives than that under pure-profit incentives for correlated products. In combination with Proposition 4, we demonstrate that the competition 
mode determines whether the CSR-related incentives increase or decrease social welfare for correlated products. The results of Section 3 and Section 4 are summarized in Table 3 as follows. 
Table 3. The summary of the results.

\begin{tabular}{|c|c|c|}
\hline & Cournot competition & Bertrand Competition \\
\hline $\begin{array}{c}\text { Incentive sensitivity } \\
\text { analysis }\end{array}$ & $\theta_{i}^{Q} \geq 0$ increases in $|\beta|$ & $\theta_{i}^{P} \leq 0$ decreases in $|\beta|$ \\
\hline Firms' profitability & $\begin{array}{c}\qquad \Pi_{i}^{Q} \geq \bar{\Pi}_{i}^{Q} \text { if } \beta \in(-1,0) \text {, with } \\
\text { equality holding if and only if } \beta=0 \text {. } \\
\qquad \Pi_{i}^{Q}<\bar{\Pi}_{i}^{Q} \text { if } \beta \in(0,1)\end{array}$ & $\begin{array}{l}\Pi_{i}^{P} \leq \bar{\Pi}_{i}^{P} \text { if } \beta \in(-1,0), \\
\text { with equality holding if and } \\
\qquad \text { only if } \beta=0 . \\
\Pi_{i}^{P}>\bar{\Pi}_{i}^{P} \text { if } \beta \in(0,1) .\end{array}$ \\
\hline Consumer surplus & $\begin{array}{c}C S^{Q} \geq \overline{C S}^{Q}, \text { with equality holding if } \\
\text { and only if } \beta=0 .\end{array}$ & $\begin{array}{r}C S^{P} \leq \overline{C S}^{P} \text {, with equality } \\
\text { holding if and only if } \beta=0 .\end{array}$ \\
\hline Social welfare & $\begin{array}{c}S W^{Q} \geq \overline{S W}^{Q}, \text { with equality holding } \\
\text { if and only if } \beta=0 .\end{array}$ & $\begin{array}{l}S W^{Q} \leq \overline{S W}^{Q} \text {, with equality } \\
\text { holding if and only if } \beta=0 .\end{array}$ \\
\hline
\end{tabular}

\section{Concluding remarks}

This paper investigates the strategic design of CSR-related managerial incentives in a duopoly and examines both Bertrand and Cournot competition modes. We first analyze whether the profit-driven firm owners have motivation to design CSR-related incentives and, then, study how such incentives affect the firms' profitability, consumer surplus, and social welfare by comparing with the benchmark pure-profit incentives.

In equilibrium, we find that both owners always employ the CSR-related incentives for their managers, with the equilibrium reducing to the pure-profit (no CSR) incentives if the products are independent. With correlated products, equilibrium analysis suggests that the firms are CSRfriendly under Cournot competition and CSR-unfriendly under Bertrand competition. By comparing with the benchmark pure-profit (no CSR) incentives we obtain the following managerial insights. First, the impact of the CSR-related managerial incentive design on the firms' profitability depends on both the competition mode and product relationship. Second, the mode of competition is the only determinant for the impact of the CSR-related managerial incentive design on consumer surplus and social welfare. 
Several possible extensions can be carried out in future research. First, the duopolistic setting can be extended to an oligopolistic framework to examine the effect of the number of firms on the CSR-related managerial incentive design. Second, this paper focuses on horizontal competition, while further research can investigate a vertical market structure in the context of supply chains. Third, we consider the simultaneous incentive design problem here, but sequential incentive design warrants further research. Finally, it is also worthwhile to examine incentive design with asymmetric firms.

\section{Appendix}

\section{Proof of Proposition 1.}

First, It is trivial to verify that $\theta_{i}^{Q}=0$ if $\beta=0$. Next, we prove $\theta_{i}^{Q}>0$ if $\beta \in(-1,0) \cup(0,1)$. Simple calculation shows that, both the denominator and numerator of $\theta_{i}^{Q}$ are positive if $\beta \in(-1,0) \cup(0,1)$.

Second, based on the solutions in Table 1, we have

$$
\Pi_{O i}^{Q}-\bar{\Pi}_{O i}^{Q}=\frac{4(1+\beta)\left[-2-4 \beta-2 \beta^{2}-\beta^{3}+(1+\beta) \sqrt{4+8 \beta+4 \beta^{2}+\beta^{4}}\right] \alpha^{2}}{(2+\beta)^{2}\left(2-\beta^{2}+\sqrt{4+8 \beta+4 \beta^{2}+\beta^{4}}\right)^{2}}, i=1,2 .
$$

It can be verified that $\Pi_{O i}^{Q}-\bar{\Pi}_{O i}^{Q}>0$ (a win-win outcome) for $\beta \in(-1,0)$ (products are complementary) and $\Pi_{O i}^{Q}-\bar{\Pi}_{O i}^{Q}<0$ (a lose-lose outcome) for $\beta \in(0,1)$ (products are substitutable).

\section{Proof of Proposition 2.}

Since $\frac{\partial \theta_{i}^{Q}}{\partial \beta}=\frac{\beta(2+\beta)\left(\sqrt{4+8 \beta+4 \beta^{2}+\beta^{4}}-\beta^{2}\right)}{2 \sqrt{4+8 \beta+4 \beta^{2}+\beta^{4}}(1+\beta)^{2}}$ has the same sign as $\beta$, which means $\theta_{i}^{Q}$ decreases in $\beta$ when $\beta \in(-1,0)$ (products are complementary), and increases in $\beta$ when $\beta \in(0,1)$ (products are substitutable). 


\section{Proof of Proposition 3.}

It is easy to verify that $C S^{Q}=\overline{C S}^{Q}$ if $\beta=0$. Next, we consider the case that $\beta \neq 0$.

$$
C S^{Q}-\overline{C S}^{Q}=\frac{2(1+\beta)\left[4+4 \beta+2 \beta^{2}-\beta^{4}-\left(2-\beta^{2}\right) \sqrt{\beta^{4}+4 \beta^{2}+8 \beta+4}\right] \alpha^{2}}{(2+\beta)^{2}\left(2-\beta^{2}+\sqrt{\beta^{4}+4 \beta^{2}+8 \beta+4}\right)^{2}} .
$$

Since the term in the square brackets in the numerator is always positive for $\beta \in(-1,0) \cup(0,1)$, we have $C S^{Q}-\overline{C S}^{Q}>0$.

\section{Proof of Proposition 4.}

One can easily check that $S W^{Q}=\overline{S W}^{Q}$ if $\beta=0$. Next, we examine the case that $\beta \neq 0$.

$$
S W^{Q}-\overline{S W}^{Q}=\frac{2(1+\beta)\left[-\beta^{4}-4 \beta^{3}-6 \beta^{2}-12 \beta-4+\left(\beta^{2}+4 \beta+2\right) \sqrt{\beta^{4}+4 \beta^{2}+8 \beta+4}\right] \alpha^{2}}{(2+\beta)^{2}\left(2-\beta^{2}+\sqrt{\beta^{4}+4 \beta^{2}+8 \beta+4}\right)^{2}} .
$$

As the term in the square bracket in the numerator is always positive for $\beta \in(-1,0) \cup(0,1)$, we can verify that $S W^{Q}-\overline{S W}^{Q}>0$.

\section{Proof of Proposition 5.}

First, it is easy to verify that $\theta_{i}^{P}=0$ if $\beta=0$ and $\theta_{i}^{P}<0$ if $\beta \in(-1,0) \cup(0,1)$. Second, based on the solutions in Table 2, we have

$$
\Pi_{O i}^{P}-\bar{\Pi}_{O i}^{P}=\frac{\left[\sqrt{1-\beta^{2}}-(1-\beta)^{2}\right] \beta^{2} \alpha^{2}}{2(1+\beta)(2-\beta)^{2}\left(1+\sqrt{1-\beta^{2}}\right)^{2}}, i=1,2 .
$$

One can see that $\Pi_{O i}^{P}-\bar{\Pi}_{O i}^{P}<0$ (a lose-lose outcome) for $\beta \in(-1,0)$ (products are complementary) and $\Pi_{O i}^{P}-\bar{\Pi}_{o i}^{P}>0$ (a win-win outcome) for $\beta \in(0,1)$ (products are substitutable).

\section{Proof of Proposition 6.}


Since $\frac{\partial \theta_{i}^{P}}{\partial \beta}=-\frac{\beta}{(1+\beta)^{3 / 2}}$ has the opposite sign to $\beta$, which means $\theta_{i}^{P}$ increases in $\beta$ when $\beta \in(-1,0)$ (products are complementary) and decreases in $\beta$ when $\beta \in(0,1)$ (products are substitutable).

\section{Proof of Proposition 7.}

If $\beta=0$, it is easy to see that $C S^{P}=\overline{C S}^{P}$. If $\beta \neq 0$, we have

$$
C S^{P}-\overline{C S}^{P}=\frac{(1-\beta)\left(2-3 \beta^{2}+\beta^{3}-2 \sqrt{1-\beta^{2}}\right) \alpha^{2}}{(1+\beta)(2-\beta)^{2}\left(1-\beta+\sqrt{1-\beta^{2}}\right)^{2}} .
$$

Thus, we verify that $C S^{P}-\overline{C S}^{P}<0$ if $\beta \in(-1,0) \cup(0,1)$.

\section{Proof of Proposition 8.}

If $\beta=0$, it is trivial to check that $S W^{P}=\overline{S W}^{P}$. If $\beta \neq 0$, one has

$$
S W^{P}-\overline{S W}^{P}=-\frac{\beta^{2}(1-\beta)\left(3-2 \beta+\sqrt{1-\beta^{2}}\right) \alpha^{2}}{2(1+\beta)(2-\beta)^{2}\left(1+\sqrt{1-\beta^{2}}\right)^{2}} .
$$

Therefore, we can confirm that $S W^{P}-\overline{S W}^{P}<0$ for $\beta \in(-1,0) \cup(0,1)$.

\section{References}

Ageron, B., Gunasekaran, A., Spalanzani, A., 2012. Sustainable supply management: an empirical study. International Journal of Production Economics 140(1), 168-182.

Aggarwal, R., Samwick, A., 1999. Executive compensation, strategic competition, and relative performance evaluation: theory and evidence. Journal of Finance 54(6): 1999-2042.

Amaeshi, K.M., Osuji, O.K., Nnodim, P., 2008. Corporate social responsibility in supply chains of global brands: a boundaryless responsibility? Clarifications, exceptions and implications. Journal of Business Ethics 81(1), 223-234.

Asseburg, H. Hofmann, C., 2010. Relative performance evaluation and contract externalities. OR spectrum 32(1), 1-20. 
Barcos, L., Barroso, A., Surroca, J., Tribó, J.A., 2013. Corporate social responsibility and inventory policy. International Journal of Production Economics 143(2), 580-588.

Barros, F., 1995. Incentive schemes as strategic variables: an application to a mixed duopoly. International Journal of Industrial Organization 13(3), 373-386.

Berrone, P., Gomez-Mejia, L.R., 2009. The pros and cons of rewarding social responsibility at the top. Human Resource Management 48(6), 959-971.

Boyd, D.E., Spekman, R.E., Werhane, P., 2005. Corporate social responsibility and global supply chain management: a normative perspective. Working paper. University of Virginia.

Boyd, D.E., Spekman, R.E., Kamauff, J.W., Werhane, P., 2007. Corporate social responsibility in global supply chains: a procedural justice perspective. Long Range Planning 40(3), 341356.

Brand, B., Grothe, M., 2013. A note on 'corporate social responsibility and marketing channel coordination'. Research in Economics 67(4), 324-327.

Brander, J.A., Zhang, A., 1990. Market conduct in the airline industry: an empirical investigation. The RAND Journal of Economics, 567-583.

Brander, J.A., Zhang, A., 1993. Dynamic oligopoly behavior in the airline industry. International Journal of Industrial Organization, 11(3), 407-435.

Carter, C.R., Kale, R. Grimm, C.M., 2000. Environmental purchasing and firm performance: an empirical investigation. Transportation Research Part E: Logistics and Transportation Review 36(3), 219-228.

Carter, C.R. Jennings, M.M., 2002. Social responsibility and supply chain relationships. Transportation Research Part E: Logistics and Transportation Review 38(1), 37-52.

Carroll, A.B., Shabana, K.M, 2010. The business case for corporate social responsibility: a review of concepts, research and practice. International Journal of Management Reviews 12(1), 85-105.

Coombs, J.E., Gilley, K.M., 2005. Stakeholder management as a predictor of CEO compensation: main effects and interactions with financial performance. Strategic Management Journal 26(9), 827-840.

Cruz, J.M., 2008. Dynamics of supply chain networks with corporate social responsibility through integrated environmental decision-making. European Journal of Operational Research 184(3), 1005-1031. 
Cruz, J.M., Wakolbinger, T., 2008. Multi-period effects of corporate social responsibility on supply chain networks, transaction costs, emissions, and risk. International Journal of Production Economics 116(1), 61-74.

Dahlsrud, A., 2008. How corporate social responsibility is defined: an analysis of 37 definitions. Corporate social responsibility and environmental management 15(1), 1-13.

Du, N., Heywood, J.S., Ye, G., 2013. Strategic delegation in an experimental mixed duopoly. Journal of Economic Behavior \& Organization 87, 91-100.

Fershtman, C., 1985. Managerial incentives as a strategic variable in duopolistic environment. International Journal of Industrial Organization 3(2), 245-253.

Fershtman, C., Judd, K., 1987. Equilibrium incentives in oligopoly. American Economic Review 77(5), 927-940.

Goering, G.E., 2007. The strategic use of managerial incentives in a non-profit firm mixed duopoly. Managerial and Decision Economics 28(2), 83-91.

Goering, G.,E., 2008a. Socially concerned firms and the provision of durable goods. Economic Modelling 25(3), 575-583.

Goering, G.,E., 2008b. Welfare impacts of a non-profit firm in mixed commercial markets. Economic Systems 32(4), 326-334.

Goering, G.E., 2010. Corporate social responsibility, durable-goods and firm profitability. Managerial and Decision Economics 31(7): 489-496.

Goering, G.E., 2012. Corporate social responsibility and marketing channel coordination. Research in Economics 66(2), 142-148.

Goering, G.E., 2013. The profit-maximizing case for corporate social responsibility in a bilateral monopoly. Managerial and Decision Economics 35(7), 493-499.

Heywood, J.S., Ye, G., 2009. Delegation in a mixed oligopoly: the case of multiple private firms. Managerial and Decision Economics 30(2), 71-82.

Hsueh, C.-F., 2015. A bilevel programming model for corporate social responsibility collaboration in sustainable supply chain management. Transportation Research Part E: Logistics and Transportation Review 73, 84-95.

Ishibashi, K., 2001. Strategic delegation under quality competition. Journal of Economics 73(1), $25-56$. 
Jansen, T., van Lier, A., van Witteloostuijn, A., 2007. A note on strategic delegation: the market share case. International Journal of Industrial Organization 25(3), 531-539.

Jansen, T., van Lier, A., van Witteloostuijn, A., 2012. Managerial bonus systems in a differentiated duopoly: a comment. Managerial and Decision Economics 33(1), 61-70.

Joh, S., 1999. Strategic managerial incentive compensation in Japan: relative performance evaluation and product market collusion. Review of Economics and Statistics 81(2), 303-313.

Kopel, M., Brand, B., 2012. Socially responsible firms and endogenous choice of strategic incentives. Economic Modelling 29(3), 982-989.

Kopel, M., Marini, M.A., 2014. Strategic delegation in consumer cooperatives under mixed oligopoly. Journal of Economics 113(3), 275-296.

KPMG, 2008.www.kpmg.eu/docs/Corp_responsibility_Survey_2008.pdf.

Lee, M.P., 2008. A review of the theories of corporate social responsibility: its evolutionary path and the road ahead. International Journal of Management Reviews 10(1), 53-73.

Lijesen, M.G., 2004. Adjusting the Herfindahl index for close substitutes: an application to pricing in civil aviation. Transportation Research Part E: Logistics and Transportation Review, 40(2), 123-134.

Mahoney, L.S., Thorn, L., 2006. An examination of the structure of executive compensation and corporate social responsibility: A Canadian investigation. Journal of Business Ethics 69(2), 149-162.

Miao, Z., Cai, S., Xu, D., 2012. Exploring the antecedents of logistics social responsibility: a focus on Chinese firms. International Journal of Production Economics 140(1), 18-27.

Miller, N.H., Pazgal, A.I., 2001. The equivalence of price and quantity competition with delegation. RAND Journal of Economics 32(2), 284-301.

Miller, N., Pazgal, A., 2002. Relative performance as a strategic commitment mechanism. Managerial and Decision Economics 23(2): 51-68.

Ni, D., Li, K.W., 2012. A game-theoretic analysis of social responsibility conduct in two-echelon supply chains. International Journal of Production Economics 138(2), 303-313.

Ni, D., Li, K.W., Tang, X., 2010. Social responsibility allocation in two-echelon supply chains: insights from wholesale price contracts. European Journal of Operational Research 207(3), 1269-1279. 
Oum, T.H., Zhang, A., Zhang, Y., 1993. Inter-firm rivalry and firm-specific price elasticities in deregulated airline markets. Journal of Transport Economics and Policy, 171-192.

Overvest, B.M., Veldman, J., 2008. Managerial incentives for process innovation. Managerial and Decision Economics 29(7), 539-545.

Panda, S., 2014. Coordination of a socially responsible supply chain using revenue sharing contract. Transportation Research Part E: Logistics and Transportation Review 67, 92-104.

Panda, S., Modak, N.M., Basu, M., Goyal, S.K., 2015. Channel coordination and profit distribution in a social responsible three-layer supply chain. International Journal of Production Economics, 168, 224-233.

PriceWaterhouseCoopers, 2010. http://www.pwc.com/ca/en/sustainability/publications/csrtrends-2010-09.pdf.

PriceWaterhouseCoopers, 2011. http://www.pwc.com/gx/en/managing-tomorrows-people/futureof-work/key-findings.jhtml.

Porter, M.E., Kramer, M.R., 2006. The link between competitive advantage and corporate social responsibility. Harvard business review, 84(12), 78-92.

Ritz, R., 2008. Strategic incentives for market share. International Journal of Industrial Organization 26(2), 586-597.

Schreck, P., 2011. Reviewing the business case for corporate social responsibility: new evidence and analysis. Journal of Business Ethics 103(2), 167-188.

Sengul, M., Gimeno, J., Dial, J., 2012. Strategic delegation: a review, theoretical integration, and research agenda. Journal of Management 38(1), 375-414.

Singh, N., Vives, X., 1984. Price and quantity competition in a differentiated duopoly. RAND Journal of Economics 15(4), 546-554.

Sklivas, S., 1987. The strategic choice of managerial incentives. RAND Journal of Economics 18 (3), 452-458.

Tomaru, Y., Nakamura, Y., Saito, M., 2011. Strategic managerial delegation in a mixed duopoly with capacity choice: prtial delegation or full delegation. The Manchester School 79(4), 811838.

Veldman, J., Gaalman, G., 2014. A model of strategic product quality and process improvement incentives. International Journal of Production Economics 145(2), 696-701. 
Veldman, J., Klingenberg, W., Gaalman, G.J.C., Teunter, R.H., 2014. Getting what you pay for strategic process improvement compensation and profitability impact. Production and Operations Management 23(8), 1387-1400.

Vickers, J., 1985. Delegation and the theory of the firm. Economic Journal 95, 138-147.

Vogel, D.J., 2005. Is there a market for virtue? The business case for corporate social responsibility. California Management Review 47(4), 19-45.

Wang, L.F., Wang, Y.C., Zhao, L., 2009. Market share delegation and strategic trade policy. Journal of Industry, Competition and Trade 9(1), 49-56.

White, M.D., 2001. Managerial incentives and the decision to hire managers in markets with public and private firms. European Journal of Political Economy 17(4), 877-896.

Xia, Y., Zu, X., Shi, C., 2015. A profit-driven approach to building a "people-responsible" supply chain. European Journal of Operational Research 241(2), 348-360.

Ye, G., Mukhopadhyay, S.K., 2013. Role of demand-side strategy in quality competition. International Journal of Production Economics 145(2), 696-701. 